\title{
Research
}

\section{The Network Governance of Urban River Corridors}

\author{
$\underline{\text { Alison R. Holt }}^{1}$, Peter Moug $^{l}$ and David N. Lerner $^{1}$
}

ABSTRACT. Urban centers can provide important ecosystem services to society both through green spaces and river corridors. However, urbanization has impacted rivers, and as a consequence, there is increasing support for their sustainable management. The governance of urban river corridors reflects a trend toward stakeholder participation and partnership working in urban regeneration. The integration of ecological, social, and economic knowledge required for their sustainable management is achieved through networks of people and organizations that cross multiple sectors. However, little is known about the structure and function of such governance networks. We address this through a case study that explores the network structure of a multistakeholder collaboration tasked with developing a city-wide strategy for the sustainable management of urban river corridors in Sheffield, UK. We combine interpretive policy analysis and social network analysis to reveal the network structure and leadership characteristics of the group. We aim to explain why the group are having difficulty reaching a shared strategic vision for the river corridors and why they feel the group lacks representativeness. Our findings show that the network needs to become better connected to support an ongoing process of deliberation and negotiation for a shared vision. In addition, there is a limited diversity of stakeholders that will affect the legitimacy of the group and their ability to manage for a range of ecosystem services of benefit across society. We conclude that governance processes need to account for a diversity of actors that may change through time, and link regional and city networks to local interests.

Key Words: ecosystem services; interpretive policy analysis; leadership; legitimacy; network governance; social network analysis; urban river corridors

\section{INTRODUCTION}

Urban ecosystems are important for the production of services that are the basis for economic development and social wellbeing (Daily 1997, Bolund and Hunhammar 1999, Ernstson et al. 2010). Urban centers have tended to develop around rivers (Grimm et al. 2008). This is due to the benefits that they can supply, such as land for development, food, water supply, energy, and transport opportunities (Eden and Tunstall 2006, Grimm et al. 2008). However, rivers have been impacted by urbanization, leading to pollution, high water abstraction, culverting, and disconnection of rivers (Everard and Moggridge 2012). Consequently, there has been increased support for restoration and sustainable management of rivers. This has partly been driven by a recognition that their ecological processes and biodiversity have the potential to be managed for a number of benefits, e.g., flood protection, cultural heritage, energy production, recreation, and desirable residential and business development opportunities. Despite this, there is a dearth of research on the governance of urban ecosystem services (Ertnstson et al. 2010). Existing work in this area has focused on the management of green spaces such as parks (e.g., Ernstson et al. 2009), rather than river corridors.

Urban river governance involves a wide range of organizations from across public, private, and voluntary sectors, as a result of the integration of the ecological, economic, and social knowledge that is required to achieve their sustainable management (Wood et al. 1999, Kid and Shaw 2000). This institutional model reflects the trend toward stakeholder (here defined as influencing and affected actors (Wilcox 2004)) participation in local planning in the United Kingdom (UK) and the European Union (EU) (Piper 2005), and partnership working in urban regeneration projects (Healey 1998). The objective is to involve local stakeholders in projects from the outset and increase accountability and democratic involvement (Healey 2003). The multifunctional nature of urban river corridors means there is competition for access to their resources (Piper 2005). Any system of governance for managing urban river corridors contains within it a range of values and opinions that may often be conflicting. For example, riverside development is not likely to promote biodiversity conservation or flood alleviation, and recreational activities may not always be complementary. Ongoing processes of governance need to be flexible enough to address the complex and dynamic nature of the environment, but stable enough to promote trust and legitimacy among stakeholders (Sandström and Rova 2010b).

Implicit within stakeholder participation and partnership working is the assumption that "networks" is an appropriate metaphor to describe their structure and is, therefore, related to the theories of network governance and social networks (Rhodes 2000, Carlsson and Sandström 2008, Marin and Berkes 2010, Sandström and Rova 2010b). Only a few studies have explored new developments in governance in the context of the environment (Crona and Bodin 2006, Newig and Fritsch 2009), and there has been an increasing focus on network approaches to analyzing social-ecological systems and the governance of natural resources (Carlsson and Sandström 2008, Hirschi 2010, Crona and Hubacek 2010, Sandström and 
Rova 2010a,b, Bodin and Prell 2011). However, there is a clear need for more empirical analyses of governance networks in order to understand the sort of institutional structures and processes that promote the sustainable management of ecosystem services (Carlsson and Sandström 2008, Bodin and Crona 2009, Crona and Hubacek 2010, Sandström and Rova 2010b). In particular, little is known about the structure and function of networks in the context of urban river corridor governance.

In this paper, we aim to further an understanding of the network governance of urban river corridors, and more broadly within natural resource management, through a case study exploring the network structure of a group responsible for creating a strategy for the sustainable management of urban river corridors in Sheffield, UK. Combining social network analysis (SNA) and qualitative interpretive policy analysis (IPA; see Appendix 1), we focus on how both network structure and leadership influence collaboration that facilitates the sustainable management of urban river corridor ecosystem services. Specifically, we examine (i) how well connected the network is and the level of diversity of actors involved within and outside the group, (ii) who are the influential actors and what are their motivations and attributes, and (iii) whether the perceived lack of a strategic vision and representativeness within the group can be explained by the network structure and the nature of leadership, and its consequences for ecosystem service governance in urban river corridors.

\section{Theory}

The study draws on theories of network governance, policy networks, and leadership. The framework on which this study is based assumes that the structure of networks (the pattern of relationships among actors in a social network), the features of institutions (formal and informal), and processes of collaboration associated with governance and management of urban river corridors are interrelated. Therefore, the structure of governance networks is an important factor in understanding the features of institutions and processes that lead to successful (or unsuccessful) sustainable management of ecosystem services. Governance networks potentially widen the scope of resources, material, and information that actors can access (Rhodes and Marsh 1992). Also, through the development of relationships among actors, they facilitate knowledge and the exchange of resources. Social network theory assumes that such networks influence actor agency, the actors' ability to operate in and shape the structure in which they find themselves (Ernstson et al. 2010, Crona et al. 2011). Networks are also assumed to influence, and be influenced by, the wider formal and informal social and political institutions in which they exist (Rhodes 2000, Sandström and Rova 2010b).

\section{Closure and heterogeneity}

Burt (2000) suggested that two particular structural features of networks affect their performance: network closure and structural holes. This has also been referred to as bonding and bridging (Putnam 2001, Woolcock and Narayan 2000, Bodin and Crona 2008), closure and structural holes (Burt 2000), closure and brokerage (Burt 2005), closure and heterogeneity (Sandström and Rova 2010b), depending on the theoretical context in which they have been developed. A closed network is defined as a well-connected network because there are many ties between actors in the network, or indirectly, through a common coordinating actor (Burt 2000). Network closure has been shown to facilitate collaboration and resource exchange and may help establish a process promoting common priorities and goals, as opposed to opportunistic behavior (Bodin and Crona 2009, Sandström and Rova 2010a,b). Closure is thought to produce mutual obligation and trust among actors (Coleman 1988, 1990, Putman 2001). Here, we look for structural characteristics of closure, assuming that it enhances the capacity of network collaboration in governance.

Structural holes are areas of a network that have few or no ties (Burt 2000). Ties among actors that bridge structural holes in a network are thought to be important, as such connections, usually weak ties (Granovetter 1973), are thought to link diverse groups, allowing access to heterogeneous resources, promoting actors as brokers across disconnected parts of the network, benefiting both the individual and the whole network (Burt 2001, 2005). In order to measure the bridging of structural holes empirically, we use the concept of network heterogeneity as developed by Reagans and Zuckerman (2001) and Carlsson and Sandström (2008). This concept emphasizes the importance of a high diversity of different actors in a network who are linked through crossorganizational (or boundary-spanning) interactions. We use heterogeneity as a proxy for identifying the extent to which our network consists of connections that bridge structural holes, as in Sandström and Rova $(2010 a, b)$. In doing so, we assume that heterogeneity allows information exchange and advice from different stakeholders, diversifying the knowledge resource and increasing legitimacy (Bodin and Crona 2009, Sandström and Rova $2010 a, b)$.

\section{Leadership}

With few exceptions, e.g., Purdue (2001), Hemphill et al. (2006), Bodin and Crona (2008), and Olsson et al. (2008), the idea of leadership and the role of leaders in the management of natural resources and regeneration in urban areas have been a neglected area of study. We explore leadership both by looking at the structural network position of each member of the SWSG, as it has been shown that the network position of an actor is important in natural resource governance (Crona et al. 2011), and by focusing on individual attributes and actions through an interpretist perspective. Understanding "leaders" and "leadership" can reveal the process of collaboration, as individuals who are seen as influential or who "make things happen" may be important for their ability to access resources and contacts, and initiate change to 
sustainable management (Burt 2005, Olsson et al. 2008). There are a number of different conceptualizations of leadership. Leaders and leadership are often defined in terms of leaders' personal qualities and attributes, including their abilities to be "transformational" and "transactional" actors. Others highlight the importance of context in relation to the success of leaders, and that leadership and leading are collective, shared activities. Building on recent, broadly interpretist, developments in leadership research (e.g., Alvesson and Sveningsson 2003, Collinson 2005, Kelly 2008, Crevani et al. 2010), we eschew universal, imposed definitions in favor of context-dependent and potentially fluid conceptions of personal qualities and attributes and "work" undertaken by people in the group, and how members see these in terms of shaping and influencing the development of the group, its activities, and aspirations. Here, we problematize notions of "leader" and "leadership." We contend that actors' understandings of their own and others' actions, attributes, and relationships, as well as context are better explored unencumbered by imposed (and possibly, in the eyes of actors, irrelevant) categorizations and definitions. See Appendix 2 for a further analysis of leadership.

\section{Case Study}

The city of Sheffield $\left(5322^{\prime}, 1^{\circ} 9^{\prime}\right)$, in the north of England, UK, lies at the confluence of five rivers (Fig. 1) (Dallimer et al. 2012). These rivers have a particular historical importance to the city. Originally, as a source of power, they were key to the development of Sheffield as an industrial center. The city was a major producer of steel from the early 18th century to the latter decades of the 20th century. However, industrialization and consequent urbanization led to pollution and environmental degradation (Firth 1997). In addition, the rapid industrial decline of the 1980s left large areas of previously industrialized land vacant and caused mass unemployment, leaving an urgent need for physical and social regeneration (Hey 2010). This history has led to heavily modified watercourses in the center of Sheffield, for example through canalization, culverting, and weirs. Some areas of the river corridor are still extensively industrialized (Dallimer et al. 2012). However, moves to protect and extend the green corridors along the urban rivers in the city during the 1920s, ensured the existence of the parks that surround the rivers in the south and west. Together, these contrasting areas provide a number of valued ecosystem services such as recreation (e. g., fishing, kayaking, walking, wildlife watching), habitat for biodiversity, flood protection, cultural heritage, education, industrial and urban cooling, and economic and social development potential through riverside offices and dwellings.

The Sheffield First Partnership aims to bring public, private, and voluntary sectors together with local people to deliver the City Strategy for increased prosperity and quality of life in the city. The environment arm of the Partnership recognized the
Fig. 1. The five major rivers (solid lines) running through urban Sheffield (shaded area). The inset shows the location of Sheffield within the UK.

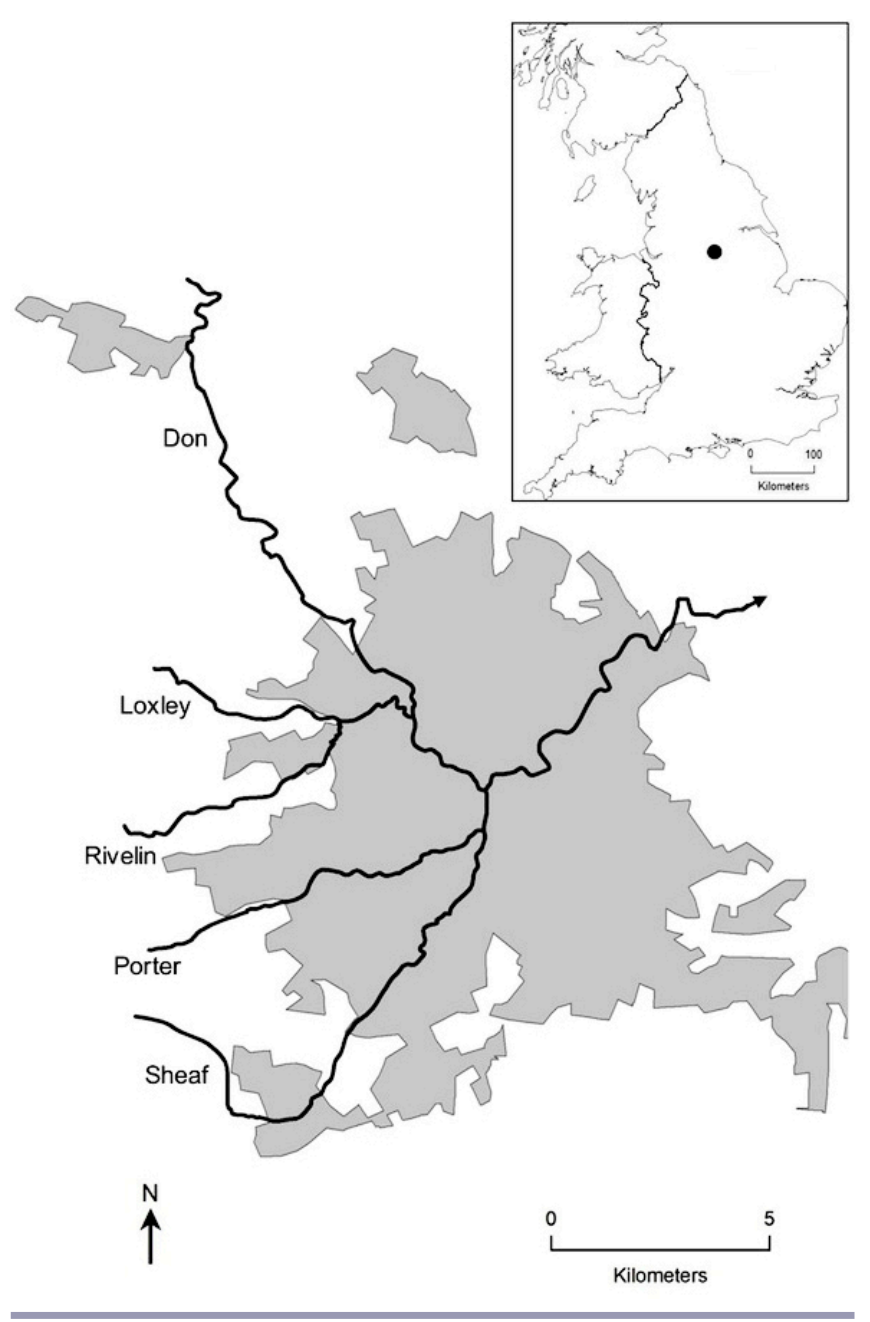

need for a group to be formed that could take a strategic overview of regenerating the city's river corridors. It was felt that the role of the river corridors in the development of Sheffield as a city had not been captured in the City Strategy, and that any economic and social regeneration should be accompanied by restoration of the river corridors. Thus, the Sheffield Waterways Strategy Group (SWSG) came into existence in 2003 to promote the coordinated regeneration of the city's waterways. The SWSG is an informal, unconstituted, multi-stakeholder collaboration. It is a group of members that represent a number of organizations across government, public, private, non-government, and voluntary sectors. Many of the group's members have established track records (some over a period of 30 years) in social and environmental regeneration activities (see Appendix 3) with a river focus in the city, both through their jobs and voluntary activities. They 
have come together to focus on common issues surrounding the urban waterways within Sheffield, to stimulate collaboration, reduce competition for funding, and develop a common vision and strategy. It is seen by its members as a forum for communication, meetings offering opportunities for the members to exchange ideas, information, and expertise. It serves an important function for the members to keep abreast of each other's activities and to have their opinions about the future of the waterways considered. The SWSG's stated objectives concern the preparation of a waterways strategy document and the facilitation of waterways regeneration initiatives across the city (Sheffield First Environment Partnership 2010). But, to date, no final version of the strategy has been published. Despite delays in the finalization of the strategy document, the SWSG played an instrumental part in setting up the River Stewardship Company in 2007, a social enterprise aiming to improve Sheffield's rivers for people and wildlife. They aim to include different individuals from a variety of groups to continue to facilitate worthwhile regeneration activities. However, there is a sense that there are shortcomings in the group's inclusiveness of the wider spectrum of Sheffield's urban river stakeholders.

\section{METHODS}

We chose to study this group as it represents an active political process with a strategic and city-wide focus. Throughout the study - from research design, through data collection, to analysis-IPA and SNA were combined or triangulated. IPA refers to a qualitative approach characterized by the critical study of the informal and hidden aspects of policy processes and institutions (for references and an explanation of the combined approach, see Appendix 1). We used IPA to understand how the group's members perceived themselves to function, and the quantitative approach to reveal through networks how the group functioned. By using SNA, we are making the assumption that the structure of the social networks influences the governance of urban river corridors (Marsh and Smith 2000, Sandström and Rova 2010b). Indeed, we assume that both structure and agency are important facets of effective natural resource governance (Schneider et al. 2003, Folke et al. 2005, Carlsson and Sandström 2008, Bodin and Crona 2009, Sandström and Rova 2010a,b).

\section{Data Collection}

We established who was involved in the strategy group by asking the organizer of the group's meetings who he routinely invited to the meetings, and then asking each of these members to add names to the list that they thought were missing, or remove those who should not be on it. This resulted in a recall list of 17 individuals who were considered to be members of the group. This is thought to be a robust way of generating self-reported ties (Ernstson et al. 2008). As we were combining SNA and IPA, two methods were combined to gather in-depth information for qualitative and quantitative analyses in an interview setting. We felt that this would ensure the participants understood the nature of the data we were trying to collect for the SNA and would limit the amount of their time that we required. Before beginning data collection, this approach was piloted in order to refine the combination of the interview and questionnaire. The structured questionnaire given to each member of the group asked about particular relationships between them, a column consisting of the names of each member of the group, and empty cells next to each name for each member to mark their relationships to others. These relational questions were wide ranging but chosen to capture important aspects of governance and the functioning of the group, e.g., frequency of contact, the type of relationship they had with each person (e.g., close friends), information exchange, advice, collaboration, trust, and influence (Table 1). The members were also asked about their links outside the SWSG. The semi-structured, in-depth interview with each member aimed to capture the purpose of the group, its objectives, impressions of how the group functioned, who the influential individuals were, how conflict was managed, and their perceptions of how successfully the group fulfilled its objectives (see Moug et al. 2012 for questionnaire and interview schedule). Interviews were held from late 2009 to early 2010. The interviews were recorded, and notes were taken. For further information on how we defined the unit of analysis and the network boundary, refer to Appendix 3.

Table 1. Relational ties measured.

\begin{tabular}{ll}
\hline \hline Relation & Question \\
\hline $\begin{array}{l}\text { Frequency of } \\
\text { contact (social }\end{array}$ & How often are you in contact with each member \\
relationships) & regeneration in Sheffield? (1-5 Likert scale)
\end{tabular}

Type of Describe your relationship with each of the relationship SWSG members.

(Acquaintance, professional relationship, work colleague, friend, close friend)

Information With whom do you most regularly exchange exchange information on regeneration issues?

Advice Who would you ask when needing expert advice on ecological or nature issues?

Who would you ask when needing expert advice on city planning issues?

Advice If you needed advice on an issue that may have regarding the potential to cause conflict between SWSG conflict members, with whom would you discuss it? 


\begin{abstract}
Collaboration With whom do you/have you collaborated on river regeneration projects or initiatives?
\end{abstract}

Trust

$$
\begin{aligned}
& \text { Who do you trust to give you reliable information } \\
& \text { on river regeneration plans and activities? }(1-5 \\
& \text { Likert scale) }
\end{aligned}
$$

Who do you trust to share your values and visions for Sheffield's waterways?

Influence

\section{Data Analysis}

A discourse analysis approach was used in the analysis of the notes and recordings, undertaken with the aid of NVIVO 8 software (see Appendix 2). The response rate to the structured questionnaire was $95 \%$; there was one individual who did not complete all of the relational questions. The relational questions were converted into network data (each individual within the strategy group representing a node in the network), one matrix for each relationship. All relational matrices were binary, with the exception of frequency of contact and trust, which were valued matrices (1-5). We used the frequency of contact relationship as the SWSG social network. We have presented the network as a whole, and as a strong and weak tie network for analyses. The strong tie network consisted of the frequent contact ties (those scoring 4 or 5), the weak tie network of the less frequent contact ties (scoring 1-3). For some analyses, the SWSG whole network was dichotomized and/or symmetrized (no direction to the ties).

We used the network-level metrics of density and centralization as empirical measures of closure. Density reflects the extent to which the individuals in a network are linked. It is measured as the number of ties present in the network, divided by the maximum number of possible ties (Wasserman and Faust 1994). Degree centralization shows how the ties are distributed among actors in the network. For example, whether the ties are all coming through one actor, or if they are evenly distributed among all actors. Degree centralization is measured by calculating the degree centrality of each of the actors, which is the number of ties connecting an actor. Next, the variation in the degree centrality of the actors was determined by summing the differences between the most central actor and each of the actors in the network. This value is then divided by the maximum possible degree centrality variation, taking into account the size of the network (Wasserman and Faust 1994). High density and/or centralization scores indicate closure. In analyzing heterogeneity, we used the number of different organizations represented by the actors in the network and the proportion of cross-boundary ties (the number of links connecting different organizations divided by the total number of links in the network) in the weak tie network as a metric. A network that has many links between individuals that represent different organizations is considered to be heterogeneous. This heterogeneity measure was limited to revealing the links to organizations represented within the group only. We wanted to understand further the extent of the group's cross-boundary ties through contact they had with organizations outside of the group. To explore this, we created a two-mode network (Wasserman and Faust 1994). Two mode networks show the relationships between two important entities (Borgatti and Everett 1997), in this case the SWSG members and individuals outside the group, with whom they are in frequent contact about urban river management issues.

We used correlations to understand if there was an association between the strong and weak ties in the SWSG network and the other relational networks (Table 1). Associations would indicate if strong or weak ties were important for trust, collaboration, and the exchange of information. QAP correlations were used due to problem of non-independence of data points in networks (Appendix 2). These and all other network analyses were performed using UCINET 6.0 (Borgatti et al. 1999) and NetDraw (Borgatti 2002) for the production of network diagrams. We treated the notion of leaders as synonymous with network centrality; and leadership as the bundle of characteristics, roles, and attributes that facilitate an actor's central position in the network. In-degree centrality, related to degree centrality (see above), is the number of ties that an actor receives from others in the network. This was calculated for each node in each relational network.

\section{RESULTS}

The IPA revealed that, although the SWSG is an institution that achieves facilitating urban river restoration activities, it is having difficulty in meeting its stated objective of creating a strategic vision of the waterways. We found that SWSG members held diverging views as to what constituted a strategy for Sheffield's river corridors. For some, strategy was associated with specific projects and the long-term interests of member organizations. Strategy in this context emerged as more than the production of a document or a goal, but a process negotiated through relationships among the members of the group:

We are struggling with the strategy. Difficulty in alighting on a shared vision; very difficult to pin that down. Most people round the table have a pet project and scheme that they want to progress with help of the group. No shared vision for the waterways. (Actor A.)

However, a central desire was for Sheffield's rivers to be a model of sustainability.

Analysis also revealed that members were questioning the inclusiveness of the process of which they were a part. The 
Fig. 2. The SWSG strong ties network. Each node is an individual person labeled with a letter, and colored according to the type of organization with which they are affiliated (red - environmental community charity, dark green - University, light green - river walk trust, dark blue - City Council, light blue - environmental regulator, black - wildlife charity, white charity promoting river recreation) and the node size reflects the in-degree centrality of the actor, the larger the circle, the more central the actor.
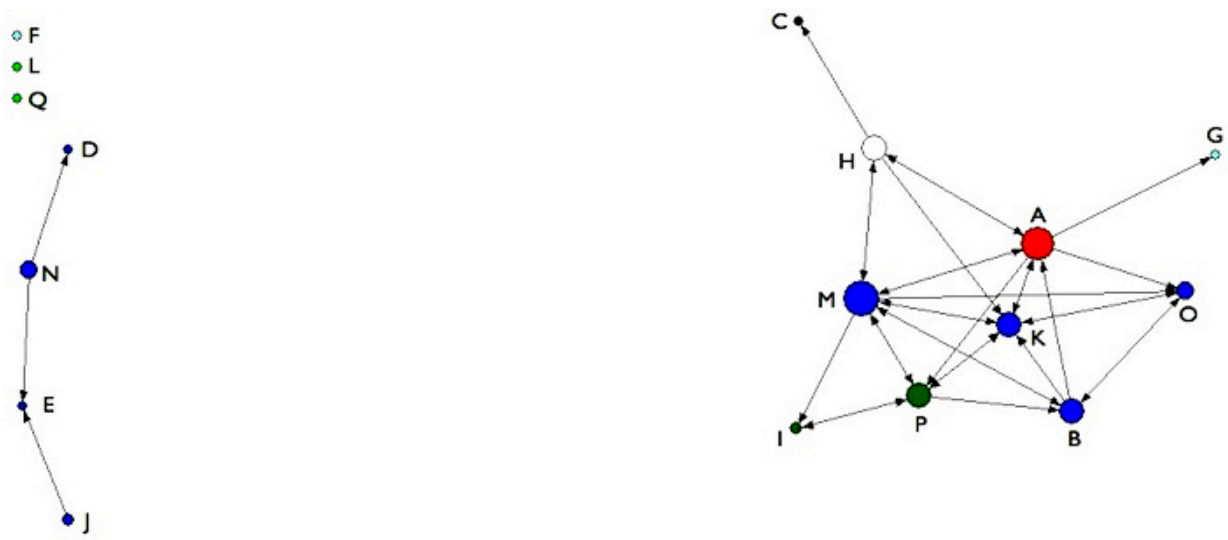

SWSG aspires to include different individuals to understand river regeneration issues and take part in particular projects. This is evident in members' claims concerning the composition, contacts, and ethos of the group. However, we found that beneath this aspiration members felt there were shortcomings in the group's representativeness or inclusiveness of the wider stakeholder set interested in the restoration of Sheffield's urban rivers. For example, one member commented "The group do have a responsibility to communicate with a wider public. They are not meeting it at the moment" (Actor N.) Other members felt that to aspire to or strive for the involvement of "all" stakeholders, particularly those with a limited geographical or interest focus was futile: "It [the SWSG] might lack relevance to those with geographically confined projects," (Actor A). Similarly, another member stated that there are "lots of friends of groups in Sheffield - into the hundreds - interested in their local area or site. Not strategic. There is not a place for them on this group - they would cease to be interested very quickly" (Actor E). Many actors at the grassroots were perceived as too parochially minded with a lack of interest and capacity to be involved with the SWSG. Views of who the SWSG should be striving to develop relationships with, focused on actors considered to be "powerful" and "influential" (such as local councillors and statutory organizations) in furthering the group and a strategic approach to river corridor management in Sheffield: "Will only work by connecting in the big important boys above [at the top of the council etc.]" (Actor C). Links with "grassroots" groups within the membership of the SWSG are long established, but the sense is, nevertheless, very much of a group that equates its development, and that of city-wide, long-term strategy with the co-opting, support, and resources associated with a certain sort of actor, or subset of stakeholders rather than a wider embracing of stakeholders. But beneath this, the group is seen as deficient in drawing a wider spectrum of stakeholders into the development of river corridor strategy, that it is somehow not living up to notions of how partnerships or collaborations ought to function. This statement sums up this tension:

Need for the Group to recognize that it's a bit of a club and needs to widen involvement, be more democratic, greater coverage across the city but also more friends in high places, people within these key organisations, key people like councillors to champion the waterways agenda for us. (Actor A.)

\section{Closure and Heterogeneity}

The SWSG social network is a dense network, with $70 \%$ of all possible ties (190) present. Network centralization is low at $24.2 \%$, showing that there is not one central actor in the network, that links are distributed more evenly among the actors. This suggests a closed network through a high density measure. However, presenting the network as a strong (frequent contact) ties only (Fig. 2), reduces the density of the network and shows two distinct components to the network, with three isolates. Within the largest component, there are two dominant actors ( $\mathrm{M}$ and $\mathrm{K}$ ) and a number of other actors, who also seem to play central roles. The smaller component is only connected to the network when the weak ties (less frequent contact) are included. This structure prevents the network being characterized by closure.

The group represents at least seven different organizations with a stake in urban river corridor management, a mixture of non-government organizations, charitable trusts, representatives 
Fig. 3. Two-mode network showing members of the SWSG (red circles) and the categories of organizations external to the group, to which their most frequent political and grassroots contacts belong. A larger symbol represents a higher number of SWSG members in touch with that organization.

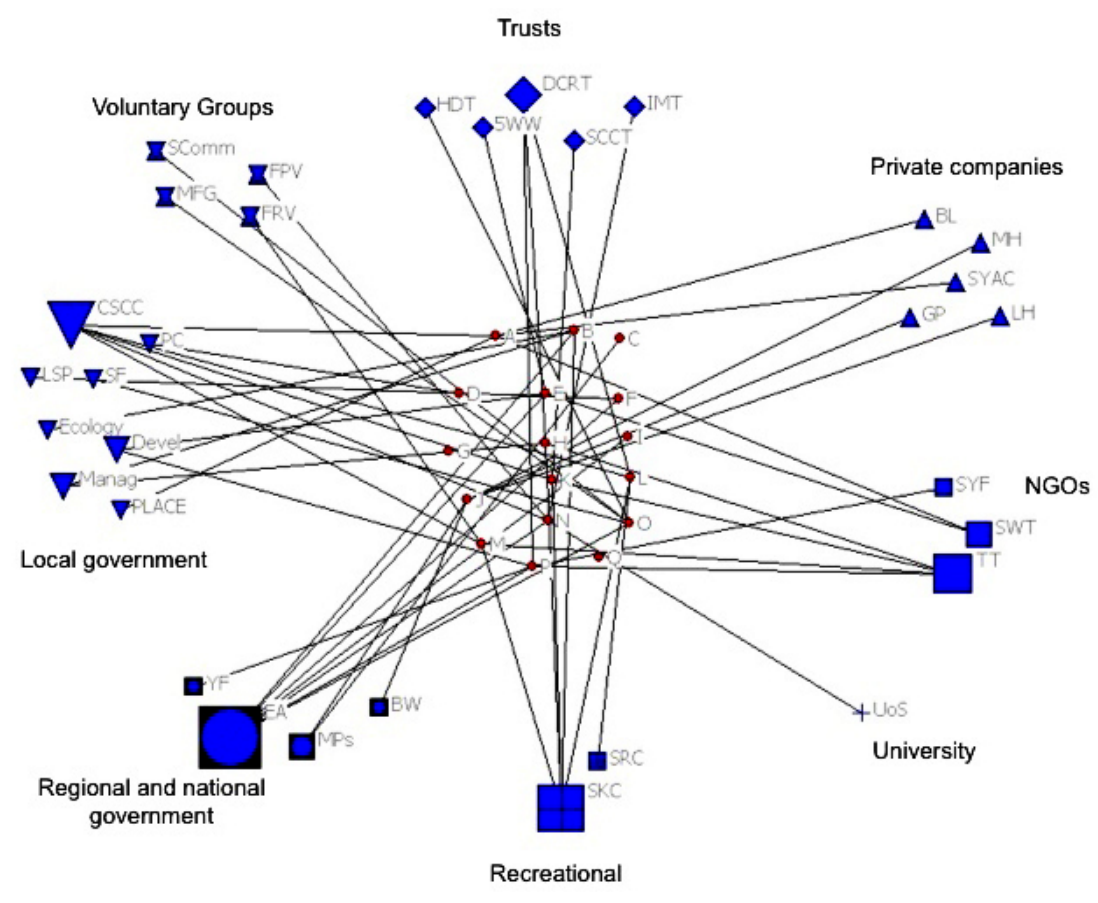

of the City Council, government environment regulatory authorities, and a university. The proportion of ties within the SWSG network that were cross-boundary exchanges between individuals that represent different organizations was $68 \%$ (114 weak ties and 16 strong ties). These two measures taken together indicate a heterogeneous network. In further exploring the potential of the group to link to external networks, the two-mode network (Fig. 3) identified 26 organizations, spanning the local government departments, regional and national government organizations, recreational groups, non-government organizations, private companies, charitable trusts, and voluntary groups. It is clear that there are more contacts with those in City Council departments, but that there are also a larger number of individuals known in the environmental government regulator, the kayak club, and the charity concerned with fish conservation. This shows further cross-boundary exchange and, therefore, a greater potential to diversify knowledge and increase legitimacy.

Clearly weak ties are important for cross-boundary exchanges. However, the significance of the stronger, more frequent, network ties was also explored. Sixty-three percent of ties in the SWSG network are between actors that consider themselves to be friends or close friends. We found that 59\% of the ties in the strong tie network (Fig. 2) were between friends or close friends, and that a much lower proportion (17\%) of the weak tie network (Fig. 4) consisted of these ties.
This indicates that the members interact on waterways management issues more often if they are already well acquainted, emphasizing the importance of trust. The relational networks of trust and information exchange correlated more significantly with those actors who more frequently communicated (strong ties) (Table 2). Information exchange was negatively correlated with weak ties. There was no correlation at all between strong ties and the ecological advice networks, or between weak ties and trust in conflict situations and city planning advice.

\section{Network Centrality and Leaders}

We took an in-depth look at centrality to explore the notions of leaders and leadership within the group's membership. The in-degree centrality score for each node across all the relationships was consistent (Table 3). Actors $\mathrm{M}$ and $\mathrm{K}$ were consistently the most central actors in the networks. However, as the high coefficient of variation in the regular exchange and frequent contact network suggests, they do not completely dominate. The distribution of these scores was relatively even among the next eight actors (P,A,C,B,O,G,H,F). This suggests that there are no clear leaders of the group, but that there are a number of people that have important roles to play in taking the group forward. 
Fig. 4. SWSG weak ties network, with each node colored according to the type of organizational affiliation (red environmental community charity, dark green - University, light green - river walk trust, dark blue - City Council, light blue - environmental regulator, black - wildlife charity, white - charity promoting river walks).

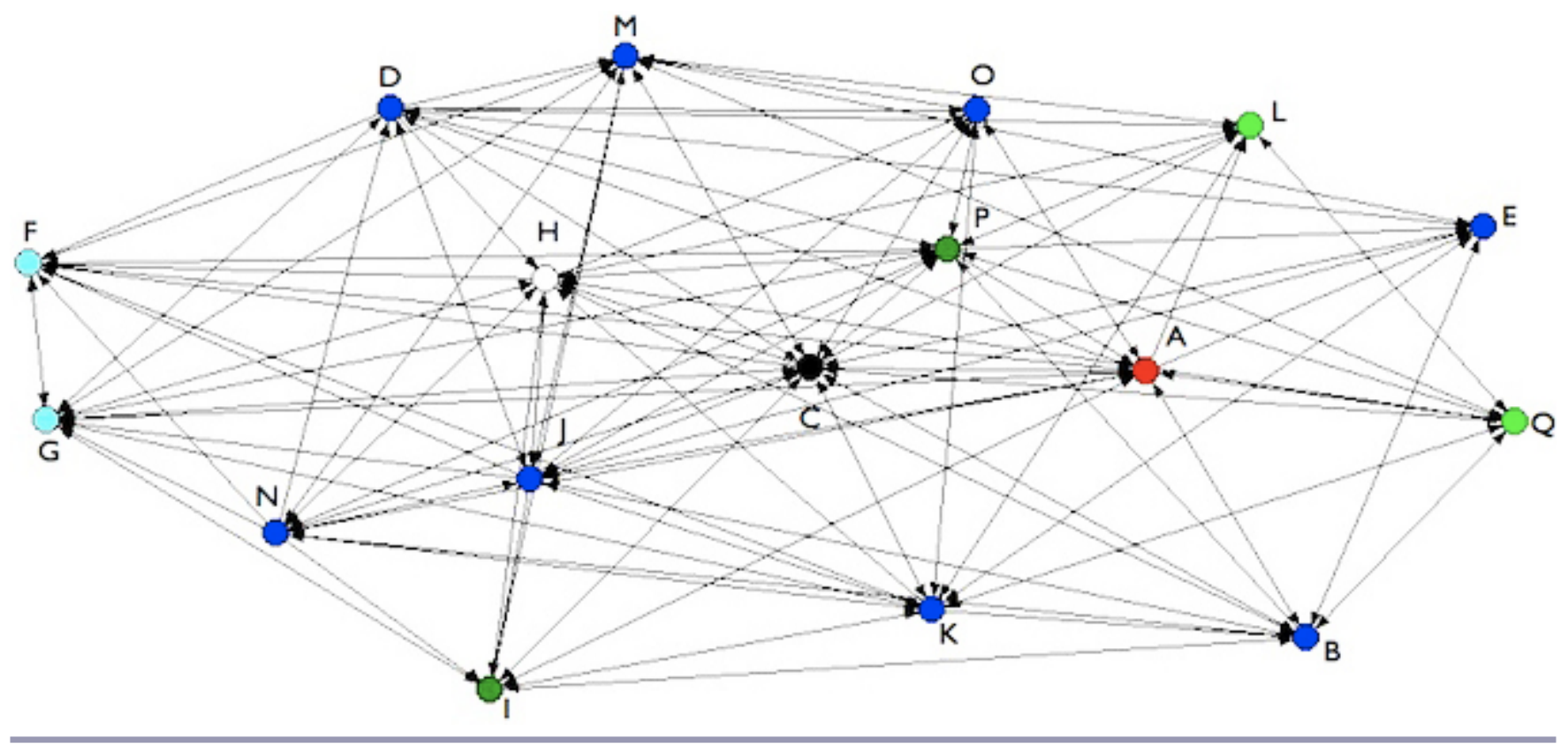

Table 2. QAP correlations between strong and weak frequency of communication relationships and those of trust and information exchange.

\begin{tabular}{lll}
\hline \hline & Strong ties & Weak ties \\
\hline Reliable information & $0.871^{* * *}$ & $0.0 .683^{* * *}$ \\
Values & $0.748^{* * *}$ & $0.320^{*}$ \\
Conflict & $0.732^{* * *}$ & 0.260 \\
Regular exchange of information & $0.957^{* * *}$ & $-0.516^{*}$ \\
Ecological advice & 0.217 & $0.389^{*}$ \\
City planning advice & $0.691^{* * *}$ & 0.176 \\
Collaboration & $0.794^{* *}$ & $0.400^{*}$ \\
\hline
\end{tabular}

$n=17, * \mathrm{p}<0.05, * * \mathrm{p}<0.01, * * * \mathrm{p}<0.001$

The interpretive analysis revealed why certain actors have such central positions in the network, as well as the attributes and roles associated with them. Those actors that were the most central ( $\mathrm{M}$ and $\mathrm{K}$ ) were attributed with leader-like qualities. Formal roles and positions in the SWSG, such as chairing meetings, were less important in the bundle of attributes associated with being a leader. Instead, track records, reputations (particularly perceptions of individuals as having been successful, experienced, and well-connected "activists" in river-related issues and improvements), and positions as already established leaders or representatives of organizations in the city's wider urban river corridor network, can be associated with notions of leading in the SWSG. The "work" of these central actors being described by members as "driving [the group] forward," being "innovators," and "administrators," alongside perceptions of personal qualities.

Table 3. Mean (in-degree) centrality scores and standard errors for each of the 17 SWSG members across all relationships.

\begin{tabular}{cl}
\hline \hline Actor & Mean $( \pm$ SE) \\
\hline M & $10.3(1.18)$ \\
K & $9.8(0.95)$ \\
P & $6.5(1.09)$ \\
A & $5.9(1.13)$ \\
C & $5.7(1.17)$ \\
B & $5.2(0.88)$ \\
O & $4.7(0.70)$ \\
G & $4.4(0.87)$ \\
H & $4.4(1.10)$ \\
F & $4.3(0.92)$ \\
E & $4.1(0.87)$ \\
J & $3.6(0.91)$ \\
L & $2.7(0.70)$ \\
I & $2.6(0.78)$ \\
Q & $2.4(0.62)$ \\
D & $1.6(0.63)$ \\
N & $1.1(0.46)$ \\
\hline
\end{tabular}


We discerned two sorts of leader from member's accounts of the group, which we labeled "fixed" and "fluctuating." The fixed leadership was consistently associated with actors $M$ and $\mathrm{K}$. This pair of individuals were seen as being particularly important in the founding of the group, they each were noted veterans of river-related "activism" in Sheffield, and were perceived to connect to powerful and influential actors, both in the development of the SWSG and management of the river corridors. It is a combination of personal attributes and actions that are instrumental in these particular individuals being singled out (Table 4). In addition to actors $\mathrm{M}$ and $\mathrm{K}$, there were also other members whose roles in the group changed over time, depending on the issue being tackled. Here, involvement "fluctuates depending on what the focus is. People drift in and out depending on what issues they are doing" (Actor M). Particular attributes belonging to some or all of the group's members were mentioned concerning their commitment, dedication, and knowledge. These ripple across the membership and reinforce the sense of the SWSG as a group of leaders, and not one composed of a fixed, defined hierarchy of leaders and followers, rooted in formal positions, imposed categories, or perceptions of charismatic or heroic attributes (Table 5).

Table 4. Attributes of Actors $\mathrm{K}$ and $\mathrm{M}$.

\section{Actors $K$ and $M$}

"They were both there at the beginning"

"Taking a lead in organizing things"

"They are the people who call people (organizationally speaking)"

"Make a lot of stuff happen, have been instrumental"

"Sees them as having more power, controlling agenda and purse strings"

Actor $K$

"Coordinator and custodian"

"Involved in setting [the group] up originally"

"Has been batting around for a long time"

"A champion for waterways"

"Facilitator and enabler"

"A role in helping the group progress, Through his own actions and practical organizational things"

"Coordinates and kept the momentum going and not letting it slip away"

"Would get stuff together"

"He has access to resources and he has personally taken it on himself to organize meetings, notes, etc."

"Everyone relies on [...] to hold it together"

Actor $M$

"Has achieved an awful lot for the area"

"Most influential and longest standing relationship with Sheffield's waterways".

"[...] is significant. He is looked to for leadership"

"If $[. .$.$] hadn"t been on the council pushing for the rivers all of the time$ they would have been way down the agenda"

"A very strong character"

"You can tell rivers are a passion for him and the combination is powerful-personality and the ability to make things happen" "In and out of his professional role he has achieved an awful lot for the area and is very well respected"

"Knows what is going on and what the opportunities are"
Table 5. Attributes of SWSG members derived from interviews with the members themselves.

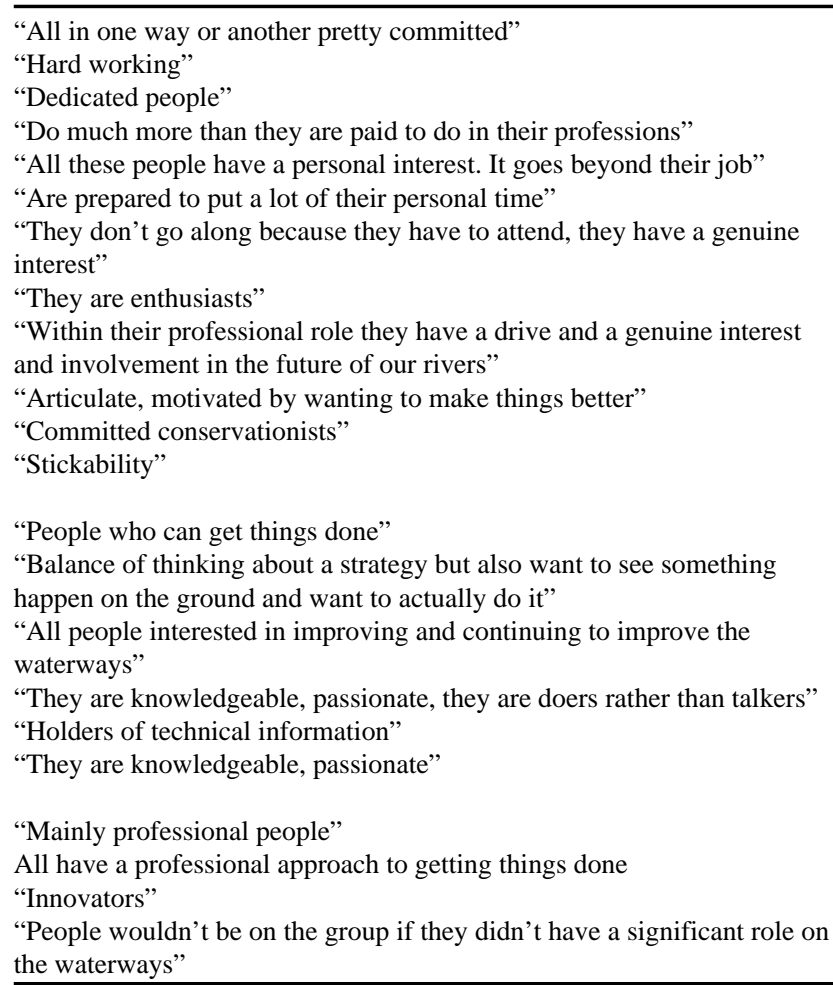

"All people interested in improving and continuing to improve the waterways"

"They are knowledgeable, passionate, they are doers rather than talkers"

"Holders of technical information"

"They are knowledgeable, passionate"

"Mainly professional people"

All have a professional approach to getting things done

"Innovators"

"People wouldn't be on the group if they didn't have a significant role on the waterways"

\section{DISCUSSION}

We have revealed the collaborative structure of a group whose aim is to formulate strategy, at the city scale, for the sustainable management of urban river corridor ecosystem services. Our analyses show that relationships among the group's members occur in a network connecting a number of different organizations interested in the enhancement of recreational opportunities, biodiversity conservation, river sustainability, and city development. More than just being representatives of collaborating organizations, many of these actors, particularly those who are frequently in contact about river regeneration issues are individuals who are friends and have a trust and respect for one another built on a history of activism and knowledge of the river corridors. There is a common passion for river regeneration in Sheffield, as the group's members have continued to work together since 2003. This network has a number of actors that play key roles in the structure. All are seen as people who can get things done, are enthusiasts for the cause, have particular expertise and knowledge, and have contacts outside the group. These actors may become more or less central through time, depending on whether their expertise fits with the issue at hand. This is thought to be a necessary feature of ecosystem management networks that build resilience (Manring 2007). Two actors stand out as being 
consistently influential. The reasons for this tie into the respect shown for their knowledge and previous successes with riverrelated projects, but also to the personal and professional ability of these individuals (both being members of the City Council, the organization that was given the remit to organize the group) to facilitate action on the river corridors.

The interviews revealed that the group is having difficulty arriving at a shared strategic vision for urban river corridor management. The lack of closure in the network may be an explanation. This may make it difficult to promote common priorities, goals (Bodin and Crona 2009, Sandström and Rova $2010 a, b)$, and, following the suggestions of Coleman (1988, 1990), trust among the members of the group. Indeed, there appears to be a struggle between the agendas of member organizations and the priorities at the city waterways scale. The two most influential members possess a holistic view and vision for the waterways that appear not to feature as strongly through the rest of the group. However, it is clear that the members of the group do share an overarching desire for achieving sustainable urban river corridors, but as yet cannot agree on exactly how this should be achieved. By its very nature, this network contains conflicting perspectives and interests, and individuals can be seen as wanting to enhance different ecosystem services (biodiversity conservation, urban planning, flood protection, recreation). The group has embarked on a collaborative process for the development of a strategy, and a resolution in the form of a strategic vision will take further deliberation and negotiation and will change through time (Carlsson and Berkes 2005, Berkes 2009).

Another tension within the group is a concern that there is a limited heterogeneity of stakeholders as members of the SWSG, raising questions of what counts as appropriate participation and legitimacy. The legitimacy of the SWSG rests on the formal and informal rules, customs, and conventions that guide the group's procedures and the usefulness of what it does, the extent to which these are justifiable, and the nature and extent of consent that the group, and its actions, have from the wider set of stakeholders (Beetham 1991). However, we recognize that what counts as legitimate is context related, contested, and open to change (Beetham 1991, Connelly et al. 2006). There are a number of organizations represented within the group, and our analyses found the network to be heterogeneous. But, this withinnetwork heterogeneity appears limited given the breadth of organizations outside of it that the members of the group are already in frequent contact with (26, Fig. 3), and more broadly, those that are interested in regeneration issues ( $>45$, Appendix $3)$. These contacts are used by the group when an issue arises for which outside expertise would be suitable. However, there was a view within the group's membership that to achieve representativeness and inclusion, a wider breadth of actors, particularly those linked to grassroots and spatially orientated interests, should be incorporated. At the moment, the view of concentrating on what are perceived as the more powerful and influential actors dominates. The legitimacy of the actions and outputs of the group (e.g., the enactment and production of a written strategy), particularly the extent to which they are judged by stakeholders to be useful, effective, and relevant, is liable to different interpretations. This is particularly important in relation to the group having a strategic, and representative, understanding for which ecosystem service benefits the river corridors should be managed, and for achieving sustainability in the long term (Hirschi 2010).

These views about the type of stakeholders that should be represented, those more powerful political contacts vs. the grassroots contacts, also show the group beginning to consider the vertical boundary spanning links (local, city, regional, and national communities, groups, and organizations) that may transform them into a bridging organization. Bridging organizations play an important role in connecting people and organizations that operate independently or as part of other networks that are not linked (Berkes 2007). A bridging organization will facilitate activity that links actors and groups who would otherwise not usually work together, because they exist on different governance levels, or they would not have a particular interest in doing so (see Hahn et al. 2006, Olsson et al. 2007, Rathwell and Peterson 2012 for examples). In this case, the SWSG as a bridging organization could connect the grassroots river corridor group interests with the members of the SWSG and that of regional- and national-level stakeholders, e.g., city councillors and Members of Parliament. The more central members of the group see this as necessary for a wider acknowledgement of the economic, ecological, and social potential of sustainable river corridor management, to gain more money and resources. However, this would require this informal group to become formally constituted, and there is a fear that this might constrain the type of activity that they have been able achieve so far (see Appendix 3). Indeed, given that the group are already struggling to reach a consensus on a strategy for the river corridors, extending the network connections both horizontally and vertically would require a greater level of coordination and leadership (Cash et al. 2006) to ensure negotiation for a common goal, but could potentially cause more conflicts of interest. This group, that has been described as a bit of a club, fear they may have less influence on the direction and activities of the group should they become a bridging organization.

The SWSG are interested in attaining sustainable urban river corridors, so that the rivers continue to provide a range of ecosystem service benefits. Managing river corridors for a variety of ecosystem services requires a foundation of sound ecological knowledge. Ecological knowledge, such as that which identifies the important river corridor functions that give rise to the valued benefits, was not exchanged well through the frequent communication ties in the network, it was 
exchanged through much less frequent ties (two of the four nodes in the second small component of the network were ecologists) (Fig. 2, Table 2). This allows the flow of ecological information but may mean that this knowledge is not considered a priority in the collaborative process. If other interests, such as city development, dominate there is a danger that the vital functions and processes that support biodiversity and services are lost.

\section{Speculation}

We suggest that the SWSG should promote wider heterogeneity through more cross-boundary ties, which may be more inclusive and promote legitimacy for the development of a city-wide strategy and management of the urban river corridors for ecosystem services relevant to different sectors of society. Widening stakeholder involvement, particularly through membership in the group, may lead to greater group flexibility, allowing them to adapt to both environmental and socioeconomic changes (Folke et al. 2005). As originally suggested by Burt $(1982,1992)$, the inclusion of a wide range of actors will encompass a diversity of views and knowledge. Without the representation of other groups, the SWSG are likely to deliver a strategy and vision that does not reflect a variety of views, and therefore, with which other sectors of society are not able to engage, and may deem inappropriate. What counts as appropriate processes, institutions, and outcomes are open to contestation among stakeholders with their varying interests, visions, and knowledge; the legitimacy of the group or what it achieves is not a foregone conclusion. Furthermore, the members require and seek legitimation (Barker 2001). Currently, the members have self-legitimized the SWSG and its activities: they decide what counts as appropriate, who does and does not join. If the group draws more individuals from other organizations into its network, then a wider range of stakeholders may express (contrary) views regarding the legitimacy of the group and its approaches to the management of Sheffield's river corridors. Here, a hybrid form of legitimacy may develop, where different visions of legitimacy concerning the SWSG, waterways strategy and management mix in fluid, dynamic, and conflictual formations (Connelly et al. 2006). At this point, the work of legitimization begins in earnest for the group's members.

It is important to see any natural resource network as having a temporal and spatial dynamic, as well as social and ecological elements. In the case of the SWSG, there are two actors who are likely to remain central, but the composition and position of other actors in the network around them may change through time. The SWSG needs to create stronger links between the members of the group to help build a shared strategic vision. Further meetings and negotiation may help to link the SWSG members into one network (rather than two components), integrating the ecological expertise. This will keep the group functional, but the participation of other individuals and organizations external to it may change over time, depending on the knowledge and expertise that is required as part of the collaborative decision making. However, in order to incorporate a variety of interests, that may be local, and important ecological functions to maintain vital services, the group could be more strategic by pinpointing links from the city scale to the grassroots level. Perhaps, in doing so, making the transition to a bridging organization. These links may reflect particular services that are valued and issues deemed of interest to different groups at multiple levels, but may also work at the same spatial scales as important ecological processes (see Ernstson et al. 2010), to ensure service delivery into the future. It is important to coordinate management at the city scale, to link from regional-level to local-scale interests. The SWSG, therefore, needs to see its strategy as one of building networks to span city, local, and regional scales, but at the same time matching this more closely with the ecological dynamics of the river corridors at these scales.

\section{CONCLUSION}

Understanding and evaluating different forms of governance for the management of urban ecosystem services is becoming more pressing as humanity becomes more urban (Bolund and Hunhammar 1999). Urban river corridors are important providers of ecosystem services (Ernstson et al. 2010), and need to be managed to reflect the diversity of requirements that society demands from them, while maintaining the ability of the system to provide them into the future. There has been a shift toward partnership and multi-stakeholder collaborations for managing urban river corridors, but little is known about how these groups function and how effective they might be. This study has gone some way to revealing this for a waterways strategy group in Sheffield, UK. We have shown, using a combination of IPA and SNA, that even within an experienced group of individuals, that are largely well thought of as people who get things done, there can be difficulties in negotiating a shared vision to achieve sustainable management. Also, including a wide range of stakeholder views and opinions within such a collaborative process may not always be seen as a priority. However, governance processes need to accommodate a diversity of actors (and accompanying interests, visions, and opinions, as well as varying capacities and abilities) that may change through time, and link regional and city networks to local interests. These networks need to consider the scales at which the ecological functions and processes that underpin services occur. This is vital for managing urban river corridor ecosystem services that represent the needs of society within environmental limits.

Responses to this article can be read online at: http://www.ecologyandsociety.org/issues/responses. php/5200 


\section{Acknowledgments:}

We would like to thank all the members of SWSG who took time to participate in the interviews, the members of URSULA Task 1 for their discussion and advice, Christina Prell, Örjan Bodin and John Skvoretz for technical advice regarding the SNA, and J. Rouquette for the production of the Sheffield river figure. This work was funded by EPSRC grants GR/S87416/01 and $E P / F 007388 / 1$.

\section{LITERATURE CITED}

Alvesson M., and S. Sveningsson. 2003. The great disappearing act: difficulties in doing "leadership". The Leadership Quarterly 14:359-381.

Barker, R. 2001. Legitimating identities. The selfpresentations of rulers and subjects. Cambridge University Press, Cambridge, UK. http://dx.doi.org/10.1017/

\section{CBO9780511490163}

Beetham, D. 1991. The legitimation of power. Macmillan, Basingstoke, UK.

Berkes, F. 2007. Community-based conservation in a globalized world. Proceedings of the National Academy of Sciences 104:15188-15193. http://dx.doi.org/10.1073/ pnas.0702098104

Berkes, F. 2009. Evolution of co-management: role of knowledge generation, bridging organizations and social learning. Journal of Environmental Management 90:16921702. http://dx.doi.org/10.1016/j.jenvman.2008.12.001

Bodin, Õ., and B. I. Crona. 2008. Management of natural resources at the community level: exploring the role of social capital and leadership in a rural fishing community. World Development 36:2763-2779. http://dx.doi.org/10.1016/j. worlddev.2007.12.002

Bodin, Õ., and B. I. Crona. 2009. The role of social networks in natural resource governance: what relational patterns make a difference? Global Environmental Change 19:366-374. http://dx.doi.org/10.1016/j.gloenvcha.2009.05.002

Bodin, Õ., and C. Prell. 2011. Social networks and natural resource management. Uncovering the social fabric of environmental governance. Cambridge University Press, Cambridge, UK. http://dx.doi.org/10.1017/CBO9780511894985

Bolund, P., and S. Hunhammar. 1999. Ecosystem services in urban areas. Ecological Economics 29:293-301. http://dx.doi. org/10.1016/S0921-8009(99)00013-0

Borgatti S. P. 2002. NetDraw: graph visualization software. Analytic Technologies, Harvard, Massachusetts, USA.
Borgatti, S. and M. G. Everett. 1997. Network analysis of 2mode data. Social Networks 19:243-269. http://dx.doi. org/10.1016/S0378-8733(96)00301-2

Borgatti S. P., M. G. Everett, and L. C. Freeman. 1999. UCINET 5.0 Version 1.00. Analytic Technologies, Natick, Massachusetts, USA.

Burt, R. S. 1982. Toward a structural theory of action. Academic Press, New York, New York, USA.

Burt, R. S. 1992. Structural holes: the social structure of competition. Harvard University Press, Cambridge, Massachusetts, USA.

Burt, R. S. 2000. The network structure of social capital. Pages 345-423 in B. M. Straw and R. I. Sutton, editors. Research in organizational behavior. Elsevier Science Inc., New York, New York, USA. http://dx.doi.org/10.1016/S0191-3085(00) 22009-1

Burt, R. 2001. Structure holes versus network closure as social capital. Pages 31-56 in K. Cook, N. Lin, and R. Burt, editors. Social capital: theory and research. Aldine de Gruyter, New York, New York, USA.

Burt, R. 2005. Brokerage and closure: an introduction to social capital. Oxford University Press, Oxford, UK.

Carlsson, L., and F. Berkes. 2005. Co-management: concepts and methodological implications. Journal of Environmental Management 75:65-76. http://dx.doi.org/10.1016/j.

jenvman.2004.11.008

Carlsson, L., and A. Sandström. 2008. Network governance of the commons. International Journal of the Commons 2:3354.

Cash, D. W., W. N. Adger, F. Berkes, P. Garden, L. Lebel, P. Olsson, L. Pritchard, and O. Young. 2006. Scale and crossscale dynamics: governance and information in a multilevel world. Ecology and Society 11(2): 8. [online] URL: http://www. ecologyandsociety.org/vol11/iss2/art8/

Coleman, J. 1988. Social capital in the creation of human capital. American Journal of Sociology 94:95-120.

Coleman, J. S. 1990. Foundations of social theory. Belknap Press, Harvard University Press, Cambridge, Massachusetts, USA.

Collinson, D. 2005. Dialectics of leadership. Human Relations 58: 1419-1442. http://dx.doi.org/10.1177/0018726705060902

Connelly, S., T. Richardson, and T. Miles. 2006. Situated legitimacy: deliberative arenas and the new rural governance. Journal of Rural Studies 22:267-277. http://dx.doi. org/10.1016/j.jrurstud.2005.11.008 
Crevani, L., M. Lindgren and J. Packendorff. 2010. Leadership not leaders: on the study of leadership as practices and interactions. Scandinavian Journal of Management 26:77-86. http://dx.doi.org/10.1016/j.scaman.2009.12.003

Crona, B., and Õ. Bodin. 2006. What you know is who you know? Communication patterns among resource users as a prerequisite for co-management. Ecology and Society 11:7. [online] URL: http://www.ecologyandsociety.org/voll1/iss 2/ $\underline{\operatorname{art} 71}$

Crona, B., H. Ernstson, C. Prell, M. Reed, and K. Hubacek. 2011. Combining social network approaches with social theories to improve understanding of natural resource governance. Pages 44-71 in Õ, Bodin and C. Prell, editors. Social networks and natural resource management. Uncovering the social fabric of environmental governance. Cambridge University Press, Cambridge, UK. http://dx.doi. org/10.1017/CBO9780511894985.004

Crona, B., and K. Hubacek. 2010. The right connections: how do social networks lubricate the machinery of natural resource governance? Ecology and Society 15:18. [online] URL: http:// www.ecologyandsociety.org/vol15/iss4/art18/

Daily, G. 1997. Nature's services: societal dependence on natural ecosystems. Island Press, Washington, D.C., USA.

Dallimer, M., J. Rouquette, A. M. J. Skinner, P. R. Armsworth, L. M. Maltby, P. H. Warren, and K. J. Gaston. 2012. Contrasting patterns in species richness of birds, butterflies and plants along riparian corridors in an urban landscape. Diversity and Distributions 18:742-753. http://dx.doi. org/10.1111/j.1472-4642.2012.00891.x

Eden, S., and S. Tunstall. 2006. Ecological versus social restoration? How urban river restoration challenges but also fails to challenge the science-policy nexus in the United Kingdom. Environment and Planning C: Government and Policy 24:661-680. http://dx.doi.org/10.1068/c0608j

Ernstson, H., S. Barthel, E. Andersson, and S. T. Borgström. 2010. Scale-crossing brokers and network governance of urban ecosystem services: the case of Stockholm. Ecology and Society 15:28. [online] URL: http://www.ecologyandsociety. org/vol15/iss4/art28/

Ernstson, H., S. Sörlin, and T. Elmqvist. 2009. Social movements and ecosystem services-the role of social network structure in protecting and managing urban green areas in Stockholm. Ecology and Society 13:39. [online] URL: http://www.ecologyandsociety.org/vol13/iss2/art39/

Everard, M., and H. L. Moggridge. 2012. Rediscovering the value of urban rivers. Urban Ecosystems 15(2):293-314. [online] URL: http://www.springerlink.com/content/ e104v035872013g8/ http://dx.doi.org/10.1007/s11252-011-0174-7
Firth, C. 1997. Domesday to the dawn of the new millennium: 900 years of the Don fishery. Environment Agency, Bristol, UK.

Folke, C., T. Hahn, P. Olsson, and J. Norberg. 2005. Adaptive governance of social-ecological systems. Annual Review of Environment and Resources 30:441-473. http://dx.doi. org/10.1146/annurev.energy.30.050504.144511

Granovetter, M. S. 1973. The strength of weak ties. American Journal of Sociology 78:1360-1380. http://dx.doi.org/10.1086/225469

Grimm N. B., S. H. Faeth N. E. Golubiewski, C. L. Redman, J. Wu, X. Bai, and J. M. Briggs. 2008. Global change and the ecology of cities. Science 319:756-760. http://dx.doi. org/10.1126/science. 1150195

Hahn, T., P. Olsson, C. Folke, and K. Johansson. 2006. Trustbuilding, knowledge generation and organizational innovations: the role of a bridging organization for adaptive comanagement of a wetland landscape around Kristianstad, Sweden. Human Ecology 34:573-592. http://dx.doi. org/10.1007/s10745-006-9035-Z

Healey, P. 1998. Building institutional capacity through collaborative approaches to urban planning. Environment and Planning A 30:153-156. http://dx.doi.org/10.1068/a301531

Healey, P. 2003. Collaborative planning in perspective. Planning Theory 2:101-123. http://dx.doi.org/10.1177/14730952030022002

Hemphill, L., S. McGreal, J. Berry, and S. Watson. 2006. Leadership, power and multisector urban regeneration partnerships. Urban Studies 43:59-80. http://dx.doi. org/10.1080/00420980500388736

Hey, D. 2010. A history of Sheffield. Third edition. Carnegie, Lancaster, UK.

Hirschi, C. 2010. Strengthening regional cohesion: collaborative networks and sustainable development in Swiss rural areas. Ecology and Society 15:16. [online] URL: http:// www.ecologyandsociety.org/vol15/iss4/art16/

Kelly, S. 2008. Leadership: a categorical mistake? Human Relations 61:763-782. http://dx.doi.org/10.1177/0018726708092403

Kidd, S., and D. Shaw. 2000. The Mersey Basin and its river valley initiatives: an appropriate model for the management of rivers? Local Environment 5:191-209. http://dx.doi. org/10.1080/13549830050009346

Manring, S. L. 2007. Creating and maintaining interorganizational learning networks to achieve sustainable ecosystem management. Organization and Environment 20:325-346. http://dx.doi.org/10.1177/1086026607305738

Marin, A., and F. Berkes. 2010. Network approach for understanding small-scale fisheries governance: the case of 
the Chilean coastal co-management system. Marine Policy 34:851-858. http://dx.doi.org/10.1016/j.marpol.2010.01.007

Marsh, D., and M. Smith. 2000. Understanding policy networks: towards a dialectical approach. Political Studies 48:4-21. http://dx.doi.org/10.1111/1467-9248.00247

Moug, P., M. Bryant, S. Connelly, A. Holt, S. MolyneuxHodgson, and L. Sharp. 2012. People theme cases: context and methodology. URSULA Project Report no. 3. ISBN 978-0-9567379-2-0. [online] URL: http://www.ursula.ac.uk/ upload/Inner/Outputs/t1_working_paper_-_cases_-_final.pdf

Newig, J., and O. Fritsch. 2009. Environmental governance: participatory, multi-level and effective? Environmental Policy and Governance 19:197-214. http://dx.doi.org/10.1002/ eet.509

Olsson, P., C. Folke, V. Galaz, T. Hahn, and L. Schultz. 2007. Enhancing the fit through adaptive co-management: creating and maintaining bridging functions for matching scales in the Kristianstads Vattenrike Biosphere Reserve, Sweden. Ecology and Society 12(1): 28. [online] URL: http://www. ecologyandsociety.org/vol12/iss1/art28/

Olsson, P., C. Folke, and T. P. Hughes. 2008. Navigating the transition to ecosystem-based management of the Great Barrier Reef, Australia. Proceedings of the National Academy of Sciences of the United States of America 105:9489-9494. http://dx.doi.org/10.1073/pnas.0706905105

Piper, J. M. 2005. Partnership and participation in planning and management of river corridors. Planning Practice and Research 20:1-22. http://dx.doi.org/10.1080/02697450500261673 Purdue, D. 2001. Neighbourhood governance: leadership, trust and social capital. Urban Studies 38:2211-2224. http:// dx.doi.org/10.1080/00420980120087135

Putnam, R. D. 2001. Bowling alone: the collapse and revival of American community. Simon and Schuster, London, UK.

Rathwell, K. J., and G. D. Peterson. 2012. Connecting social networks with ecosystem services for watershed governance: a social-ecological network perspective highlights the critical role of bridging organizations. Ecology and Society 17(2): 24. http://dx.doi.org/10.5751/ES-04810-170224 http://dx.doi.org/10.5751/ES-04810-170224

Reagans, R., and E. W. Zuckerman. 2001. Networks, diversity and productivity: the social capital of corporate R\&D teams. Organization Science 12:502-517. doi:10.1287/orsc.12.4.502.10637 http://dx.doi.org/10.1287/orsc.12.4.502.10637

Rhodes, R. A. W. 2000. Public administration and governance. Pages 54-90 in J. Pierre, editor. Debating governance. Oxford University Press, Oxford, UK.

Rhodes, R. A. W., and D. Marsh. 1992. New directions in the study of policy networks. European Journal of Political
Research 21:181-205. http://dx.doi.org/10.1111/j.1475-6765.1992. tb00294.x

Sandström, A., and C. Rova. 2010a. Adaptive co-management networks: a comparative analysis of two fishery conservation areas in Sweden. Ecology and Society 15:14. [online] URL: http://www.ecologyandsociety.org/vol15/iss3/art14/

Sandström, A., and C. Rova. 2010b. The network structure of adaptive governance-a single case study of a fish management area. International Journal of the Commons $4: 528-551$.

Schneider, M., J. Scholz, M. Lubell, D. Mindruta, and M. Edwardsen. 2003. Building consensual institutions: networks and the National Estuary Program. American Journal of Political Science 47:143-158. http://dx.doi.org/10.1111/1540-5907.00010

Sheffield First Environment Partnership. 2010. Sheffield Waterways Strategy plus an introduction to green infrastructure masterplanning. [online] URL: https://www. sheffieldfirst.com/.../Sheffield-Waterways-Report.doc

Wasserman, S., and K. Faust. 1994. Social network analysis: methods and applications. Cambridge University Press, Cambridge, UK. http://dx.doi.org/10.1017/CBO9780511815478

Wilcox, D. 2004. The guide to effective participation. Partnership Books, Brighton, UK.

Wood, R., J. Handley, and S. Kidd. 1999. Sustainable development and institutional design: the example of the Mersey Basin campaign. Journal of Environmental Planning and Management 42:341-354. http://dx.doi.org/10.1080/09$\underline{640569911127}$

Woolcock, M., and D. Narayan. 2000. Social capital: implications for development theory, research, and policy. The World Bank Research Observer 15:225-249. http://dx.doi. org/10.1093/wbro/15.2.225 
APPENDIX 1. Combining IPA and SNA.

Interpretive policy analysis (IPA) emerged from political science and planning disciplines as a critique of the uncritical positivism of much policy analysis. IPA approaches are characterised by the reflexive and critical study of the informal and hidden aspects of policy processes and institutions as sites of meaning creation and contest (Wagenaar 2011, Hajer and Wagenaar (eds.) 2003, Fischer and Forester (eds.) 1993). Research design and methods are consequently directed towards reconstructing something of actors' perceptions of particular processes through the creation, collection and analysis of qualitative data.

Social Network Analysis (SNA) is a quantitative approach to the study of social relations and their structure (Wasserman and Faust 1994, Prell 2012). This approach originated from sociology, and combines theoretical concepts, methods and analytical techniques that help reveal the structure of social relations and how these might influence social behaviour. It is built on the concept of networks, which are made up of nodes, that can represent individual people or organisations, and the ties or relations between them, that can be characterised by whatever relation is of interest to the researcer, such as friendship, trust or information exchange. SNA is becoming increasingly popular as a way of understanding how social structures might affect natural resource governance (see Bodin and Prell 2011).

In this paper, SNA and IPA are 'combined'. This endeavour concerns the attempt to co-ordinate, practically and philosophically speaking, these two approaches across the various overlapping stages of empirical research, from research design and strategy, through data creation / collection and analysis, to the writing-up and dissemination of insights and findings (Tashakkori and Teddlie, 1998). Combining also addresses the philosophical issues problems and advantages - behind the bringing together of approaches rooted in 'positivist' and 'post positivist' paradigms. Here debates about the nature of truth and knowledge, are acknowledged insofar as the approaches and their particular world views are retained and respected, and resolved to the extent that the paper is presented in a style familiar and accessible to SNA and positivist approaches more generally, with interpretist preoccupations and insights contributing to research design, data collection, triangulation, writing and dissemination. The practical combining of the SNA and IPA is founded partly on the development of an appropriate disposition and working relationship between the researchers across the research stages, and on a particular understanding of triangulation, one which elaborates on definitions which emphasise the achievement of internal validity or the 'adjudication between accounts' towards the usage of the term to denote the checking and comparison between accounts. This understanding of triangulation entails 'corroboration', the development of the internal validity or credibility of the research by checking the consistency of accounts; 'elaboration', an increase in the number of sources of data highlighting different perspectives; and 'initiation' or 'illumination' which refers to the use of non-convergent data in the development of findings (Rossman and Wilson 1985). The goal of triangulation as presented here is not necessarily about arriving at a single, clear cut account or findings regarding, in this case, the SWSG. Data may converge, but they may also diverge, and this can lead to a deeper, finer grained understanding.

\section{References}


Bodin, Ö., and C. Prell. 2011. Social networks and natural resource management.

Uncovering the social fabric of environmental governance. Cambridge University Press, UK.

Fischer, F. and J. Forester editors. 1993. The argumentative turn in policy analysis and planning. Duke University Press, USA.

Hajer, M.A., and H. Wagenaar editors. 2003. Deliberative policy analysis: understanding governance in the network society. Cambridge University Press, UK. Prell, C. 2012. Social Network Analysis: history, theory and methodology. SAGE Publications Ltd, London.

Rossman, G. B., and B. L. Wilson. 1985. Numbers and words: combining quantitative and qualitative methods in a single large-scale evaluation study. Evaluation Review 9:627-643. Tashakkori, A. and C., Teddlie. 1998. Mixed methodology. Combining qualitative and quantitative approaches. SAGE Publications Inc., USA.

Wagenaar, F. 2011. Meaning in Action: interpretation and dialogue in policy analysis. M.E. Sharp Inc. USA. Wasserman, S. and K. Faust. 1994. Social Network Analysis: methods and applications. Cambridge University Press, USA. 
APPENDIX 2. Leadership review and additional data analysis notes.

\section{Leadership review}

1. In the mainstream research on leaders and leadership - essentially positivist in nature and focussed on the qualities and attributes of 'leaders' - leadership is usually defined in general, universal terms. Recently, for example, 'transformational' and 'transactional' categorisations of leadership have been in vogue as conceptual and analytical categories (see, for example, Hemphill et al 2006, pp65-66). For Purdue (2001, p2213) 'transformational leadership' denotes the ability that leaders have to transform a situation, and 'transactional leadership' concerns the relations between leaders and followers. Debates based on transformational and transactional notions of leadership revive Weberian notions of charisma to focus on the agency of leaders, who with particular attributes and characteristics, have the capacity to make change. The idea of 'social entrepreneurs', a term sometimes used in relation to debates surrounding community development, grew out of these conceptualisations of leadership. Social entrepreneurs (a variety of community leader) 'win confidence through their reputation for competence in acquisition and management of resources, and goodwill by their personal attributes of vision, commitment and energy' (Purdue, 2001, p2215). Hemphill et al (2006, p66) argue that transformational and transactional constructions of leadership are best seen, and utilised, as complimentary in explaining the roles of leaders.

Contingency leadership is another influential approach in recent leadership research and is frequently interwoven with transformational and transactional categorisations. Theories of contingency leadership revolve around the idea that the success of a leader is contingent on the attributes of that individual and context (the setting in which the individual is embedded) (Purdue 2001, p2213). However, Grint (2005) argues that contingency theory is 'premised upon an essentialist notion of context: in other words, that we can render the context or situation transparent through scientific analysis' and in so doing the extent to which context - 'environment, the resources available and the history of the organization' - is 'actively constructed by the leader, leaders, and/or decision-makers' is neglected (p1470)

The idea of shared or distributed leadership is another strand in the study of leaders and leadership that has developed in recent years (Feyerherm 1994, Crevani et al 2007). Leadership is seen as a collective and shared activity involving actors beyond those identifiable as formal leaders in which the result is increased efficiency and effectiveness (Crevani et al 2010, p78). Thus leadership can be viewed as being rooted in relations between group members rather than as being a product of a hierarchy or a single leader (Avolio et al 2009, pp431-432).

Critical responses to mainstream leadership research have, in recent years, started to appear in the literature. These tend to adopt a broadly interpretive position (Alvesson and Sveningsson 2003, p362). Importantly, these responses share a focus on leadership as process, practice and interaction (Crevani et al 2010, p78, Barge and Fairhurst 2008, p227). This shift in perspective opens up to scrutiny prior definitions and established conceptualisations of 'leader' and 'leadership'. Underlying this 
development is a perceived need 'to be much more open than has been common about the paradigmatic assumptions, methodological preferences, and ideological commitments permeating the majority of leadership studies and writings' (Alvesson and Sveningsson 2003). For example, are notions of 'romanticised' and 'heroic' leaders and leadership concerned with legitimising particular hierarchies and inequalities (Bresnen, 1995, p499), and should taken for granted and dominant constructions of leadership be challenged as exclusive and elitist? (Crevani et al 2010, p80).

All this suggests a change of focus from conceptualisations rooted in notions of 'leaders' and 'followers' to the notion of 'leadership' as a social phenomenon (Crevani et al 2010, p78). Attempts to create fixed, universal categorisations deny that leadership in a given context may be characterised by asymmetrical and shifting power relations blurring the distinction between 'leaders' and 'followers' and highlighting issues of conflict and legitimacy (Collinson, 2005). Within research that adopts such views, definitions of leadership are consequently rare but when encountered are presented as heuristic devices, for example, leadership as 'a cocreated, performative, contextual, and attributional process where the ideas articulated in talk or action are recognised by others as progressing tasks that are important to them' (Barge and Fairhurst 2008, p232).

Rather than being concerned with defining, a more useful and interesting direction is to problematise the notion of leadership: does leadership exist beyond the definitions, categories and discourses of researchers (such as the focus on the attributes of formal leaders), for example? Alvesson and Sveningsson (2003) argue that leadership as a standalone phenomenon is 'based on a set of assumptions and a methodology that means that leadership is effectively produced: respondents are interpolated as leaders and asked to report about their leadership [...] Seldom are they asked to consider whether leadership is a relevant term or to think critically about it' (p364).

The notion of leadership - as a clear facet of relations within organisations and sociopolitical processes - is arguably more fragile and intangible than the majority of the literature assumes. It seems to 'disappear' amongst other social and organisational activities and phenomena (Alvesson and Sveningsson 2003, p379). Kelly (2008), however, challenges this view. The apparent 'fragility' of leadership may be a product of how it is researched, namely a single-minded search for leadership amongst the 'milieu of everyday life'. Leadership, according to Kelly, involves 'other kinds of work' and this 'should be of primary interest to the interpretive and reflexive researcher of leadership'. So,

depending on the activity that is examined, it may be that leadership is expressed through the holding of budget meetings, team meetings, through the telling of jokes, a chat over a coffee, giving speeches, dealing with complaints, sending e-mails, opening post and generally getting on with ordinary work (Kelly 2008, p770). 
To Grint (2005, p1471), 'leadership involves the social construction of the context that both legitimates a particular form of action and constitutes the world in the process. If that rendering of the context is successful - for there are usually contending and competing renditions - the newly constituted context then limits the alternatives available such that those involved begin to act differently'. Here leadership is linked to the power to act and constitutes a dominate discourse which is at least to some extent legitimate in the eyes of others. Grint advocates this interpretation of leadership in explicit contrast to contingent notions of leadership. Though both theories rest of notions of context, Grint's contends that attempts to arrive at objective and independent accounts of 'context, situation, leader and followers' are unsatisfactory. Instead the focus should be on the 'construction of contexts that legitimates their intended or executed actions and accounts' (Grint 2005, p1472). Building on these broadly interpretivist developments in leadership research we eschew universal, fixed definitions in favour of context dependent and fluid conceptions of leaders and leadership.

\section{Additional data analysis notes}

2. 'Discourse analysis' is a broad term used in this paper to describe the mode of analysis used in the interpretive research component of the paper. It is a variety of discourse analysis traceable to the work of Maarten Hajer (Hajer 2006, 1995, Hajer and Versteeg 2005). 'Discourse' here refers to 'a specific ensemble of ideas, concepts and categorizations that are produced, reproduced, and transformed in a particular set of practices and through which meaning is given to physical and social realities' (Hajer 1995, p44). Interview recordings and notes, were 'coded' - that is reordered and categorised - to attempt to highlight members' discourses concerning various aspects of the Group and its membership.

3. Quadratic assignment procedure (QAP) correlations were used due to general issue of non-independence of data points in networks, and is a popular method of testing the association between two networks (Prell 2012). The correlation coefficient used was Goodman-Kruskal Gamma, as the data were binary. This coefficient was computed first, then rows and columns of the matrices were randomly permuted hundreds of times to determine the proportion of random trial that would generate a coefficient as large as, or equal to, the observed coefficient.

\section{References}

Alvesson M. and S. Sveningsson. 2003. The great disappearing act: difficulties in doing "leadership". The Leadership Quarterly 14:359-381.

Avolio, B.J., Walumbwa, F.O. and T.J. Weber. 2009. Leadership: current theories, research, and future directions', Annual Review of Psychology 60: 421-429.

Barge, J.K. and G.T. Fairhurst. 2008. Living leadership: a systematic constructionist approach', Leadership 4:227-251.

Bresnen, M.J. 1995. All things to all people? Perceptions, attributions, and constructions of leadership', The Leadership Quarterly 6:495-513. 
Collinson, D. 2005. Dialectics of Leadership. Human Relations 58: 1419-1442.

Crevani, L., M. Lindgren and J. Packendorff. 2010. Leadership not leaders: on the study of leadership as practices and interactions. Scandinavian Journal of Management 26:77-86.

Feyerherm, A.E. 1994. Leadership in collaboration: a longitudinal study of two interorganizational rule-making groups', The Leadership Quarterly 5:253-270.

Grint, K. 2005. Problems, problems, problems: the social construction of "leadership". Human Relations 58:1467-1494.

Hajer, M. 1995. The politics of environmental discourse: ecological modernization and the policy process. Clarendon Press, Oxford.

Hajer, M. 2006. Doing discourse analysis: coalitions, practices, meaning. M. van den Brink and T. Metze editors. Words matter in policy and planning: discourse theory and methods in social sciences. Utrecht: Netherlands Graduate School of Urban and Regional Research.

Hajer, M. and W. Versteeg. 2005. A decade of discourse analysis of environmental politics: achievements, challenges, perspectives. Journal of Environmental Policy and Planning 7:175-184.

Hemphill, L., McGreal, S., Berry, J., and S. Watson. 2006. Leadership, power and multisector urban regeneration partnerships. Urban Studies 43:59-80.

Holland, P., and S. Leinhardt. 1970. A method for detecting structure in sociometric data. American Journal of Sociology 76:492-513.

Kelly, S. 2008. Leadership: a categorical mistake? Human Relations 61:763-782. Prell, C. 2012. Social Network Analysis: history, theory and methodology. SAGE Publications Ltd, London.

Purdue, D. 2001. Neighbourhood governance: Leadership, trust and social capital. Urban Studies 38:2211-2224. 
APPENDIX 3. Background.

\title{
1. Examples of urban river corridor regeneration projects in Sheffield, past and present, in which some Sheffield Waterways Strategy Group (SWSG) members have been involved
}

\author{
Blackburn Meadows (http://www.wild- \\ net.org/Sheffield/FolderMenu/content22.aspx?id=312) is a wetland Nature Reserve \\ created from a former sewage works, on the north-east fringe of Sheffield city.
}

Five Weirs Walk (http://www.fiveweirs.co.uk/) is an $8 \mathrm{~km}$ footpath and cycleway along the Lower Don Valley in the city of Sheffield.

Nursery Street Pocket Park, to be created this year on the River Don in the centre of Sheffield, is turning derelict land on the river floodplain into a park that will help reduce city flooding, allow public access to the river and attract development.

The River Stewardship Company (http://www.the-rsc.co.uk/) was set up by members of the SWSG. It is a social enterprise that aims to manage the waterways in Sheffield for people and wildlife.

Salmon Pastures (http://www.wildlifetrusts.org/reserves/salmon-pastures) is a Local Nature Reserve created on a former industrial site on the River Don, Sheffield city.

\section{Unit of analyses and network boundary}

The unit of analysis used in the SNA was the individual, as we believed that it was the informal relationships between individuals that had the greatest influence on how the SWSG exchanged resources and functioned. However, the organisation(s) with which each individual was affiliated was also important to consider, and was influential to how the member's perceived each other. The boundary of the network was defined by the membership of the SWSG. Although the SWSG was part of a larger network (see 3. below) of individuals participating in the regeneration of Sheffield's urban river corridors, we decided to focus on the Group itself. The individuals within the Group were seen to be key to urban river management, and we were interested in the strategic governance processes. Many of the individuals in the larger network were from groups that worked on an individual project bases, rather than with strategic management, and may have only been involved briefly or in one activity.

\section{The urban river corridor regeneration network in Sheffield}

The Sheffield urban river corridor regeneration network (Fig. A3.1), of which the members of the SWSG are a part, consists of 152 individuals spanning $>45$ different organisations, from the local government, recreation groups (walking, angling, kayaking), energy companies, environmental regulator, statuary and NGO biodiversity conservation, a natural history society, museums, water companies, landowners, and social regeneration community groups. Each node is an individual and the ties between them show who considers whom to be involved in regeneration activities in Sheffield. The diagram has been drawn with the most central actors (those with the most incoming ties) in the centre. The squares show the 17 members of the 
Sheffield Waterways Strategy Group. They are clearly well connected individuals within this wider network, and we were interested to see how they influenced the strategic governance of urban river corridor ecosystem services.

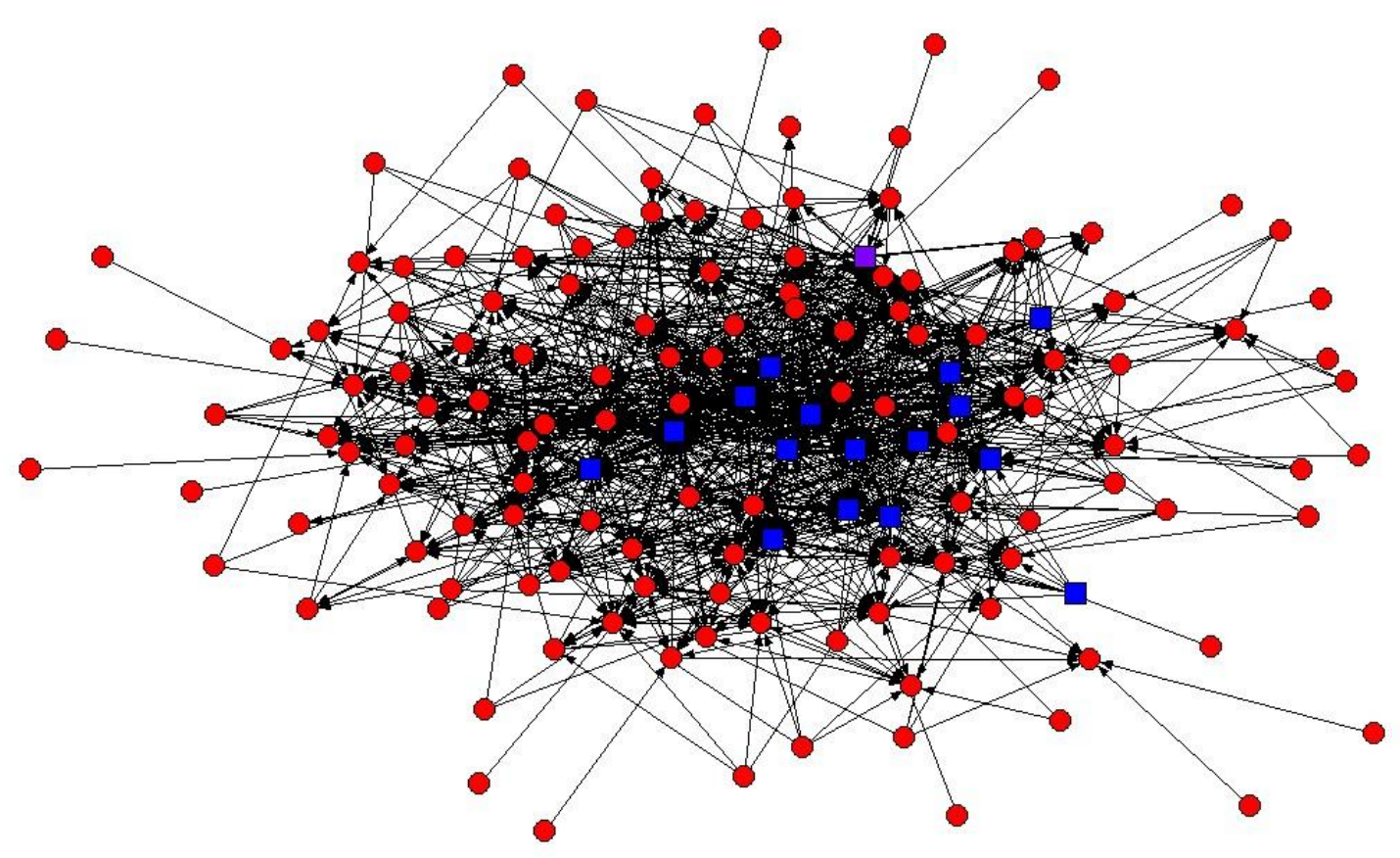

Fig. A3.1 Sheffield's urban river corridor regeneration network 